\title{
FORMAÇÃO DE TUTORES NA DEAD/IFCE: COMPETÊNCIAS E HABILIDADES NECESSÁRIAS
}

\author{
Eliana Alves Moreira Leite ${ }^{1}$, Gilvandenys Leite SAles ${ }^{1}$, \\ Cassandra Ribeiro JOYE ${ }^{1}$, CARla Anaile Moreira de Oliveira $^{1}$ \\ ${ }^{1}$ Instituto Federal de Educação, Ciência e Tecnologia do Ceará \\ <elimoreiraead@gmail.com>,<denyssales@ifce.edu.br>,<cassandra@ifce.edu.br> \\ $<$ carlaanaile@gmail.com>
}

DOI: 10.21439/conexoes.v10i2.725

\begin{abstract}
Resumo. Este artigo apresenta a metodologia aplicada para à formação de tutores que atuam em cursos de graduação na modalidade semipresencial do Instituto Federal de Educação, Ciência e Tecnologia do Ceará (IFCE-CE) através da diretoria de Educação a Distância (DEaD), integrada à Universidade Aberta do Brasil (UAB). A partir do pressuposto que o papel do tutor nessa modalidade de ensino é importante como mediador na aprendizagem do aluno, faz-se necessário que seja preparado para desenvolver competências e habilidades para desempenhar sua função. Este trabalho apresenta a formação do tutor a distância no IFCE, que por meio da interação no ambiente virtual sócio-construtivista MOODLE (Modular Object-Oriented Dynamic Learning Environment), adquire as competências pedagógicas, didáticas e tecnológicas necessárias a sua formação. O tutor precisa vivenciar estas competências no seu curso de formação pela modalidade em EAD, por meio das atividades elaboradas dentro do ambiente virtual, para posteriormente aplicá-las a seus alunos. Nesse contexto, o tutor é formado para exercer sua função de dinamizador da produção coletiva dos saberes, na perspectiva de incitar a interação dos alunos para o uso das ferramentas interativas do ambiente virtual. Espera-se com esta formação preparar profissionais aptos à mediação e interação e à formação de aprendizes autônomos.
\end{abstract}

Palavras-chaves: Formação de tutores. Competências e habilidades. Educação a distância.

\begin{abstract}
This paper presents a methodology for training tutors who work in undergraduate blended courses at Instituto Federal de Educação, Ciência e Tecnologia do Ceará (IFCE-CE) through the Diretoria de Educação a Distância (DEAD) and Universidade Aberta do Brasil (UAB). Assuming that the tutors role in this type of education is important as a mediation of student learning, it is necessary for them to be prepared to develop skills and abilities to perform their function. This paper presents the formation of the distance tutor at IFCE, who through interaction at the socio-constructivist virtual environment MOODLE (Modular Object - Oriented Dynamic Learning Environment) acquires the pedagogical, didactic and technological skills necessary for their formation. Tutors need to experience these skills in their distance learning training course through the activities developed within the virtual environment, to subsequently implement them with their students. In this context, the tutor is trained to perform his/her role to foster collective production of knowledge, with a view of encouraging student interaction for the use of interactive tools of the virtual environment. This training is expected prepare suitable mediation and interaction professionals who, in turn, help to form independent learners.
\end{abstract}

Keywords: Tutor training. Skills and abilities. Distance education.

\section{INTRODUÇÃO}

A Educação a Distância (EaD) obteve um crescimento considerável desde o final da década de 1980 e alcançou maiores proporções neste início de século. Segundo o Anuário Brasileiro Estatístico de Educação Aberta e a Distância (ABRAEAD/2008), o número de alunos que se matricularam em cursos a distância em 2007 chegou a 2,5 milhões. Os números apontam a expansão que a $\mathrm{EaD}$ vem tomando no Brasil, mas também 
passa a mostrar os cuidados que se deve ter para que de fato essa modalidade de ensino não se identifique apenas pela quantidade dos números, mas principalmente prime pela qualidade dos cursos.

Nesse contexto, as instituições de ensino, sejam públicas ou privadas, expandiram seus cursos de graduação, especializações e de extensões na modalidade da $\mathrm{EaD}$, utilizando-se dessa alternativa para alargar o acesso a todos aqueles que desejaram ampliar seus conhecimentos, mas que não possuíam tempo suficiente para estudar em uma sala convencional ou mesmo para facilitar a capacitação de profissionais que, devido as suas demandas profissionais, não possuíam condições para se deslocar a uma sala de aula.

Em se tratando das políticas públicas do governo no âmbito da educação pública, a Secretária de Educação a Distância (SEED) passou a investir na Educação a Distância (EAD) como meio para suprir a demanda da sociedade que não conseguiu chegar aos bancos da escola convencional e ainda disponibilizou diversas ações para aqueles que já estão exercendo funções, mas que não possuem uma certificação, bem como também uma forma de diminuir a desigualdade social existente em nosso país. Dentre essas ações podemos citar: Rede e-Tec Brasil, Sistema Universidade Aberta do Brasil (UAB), Pró-Licenciatura, Mídias na Educação e outros.

Em se tratando dos cursos superiores vinculados a $\mathrm{EaD}$, foram elaborados em 2003 a primeira versão dos Referenciais de Educação a Distância pelo Ministério da Educação (MEC)/SEED e em 2007 uma comissão de especialistas foi composta para sugerir mudanças no documento, dada a necessidade de atualização do documento anterior.

Os Referenciais de Qualidade para Educação Superior a Distância (BRASIL, 2007) citam os principais tópicos que devem conter o Projeto Político Pedagógico de um curso nessa modalidade, os quais são: concepção de educação e currículo no processo de ensino e aprendizagem, sistemas de comunicação, material didático, avaliação, equipe multidisciplinar, Infraestrutura de apoio, gestão acadêmico-administrativa, sustentabilidade financeira.

O documento ainda deixa bem claro que o aluno é o centro do processo educacional e que um dos pilares para garantir a qualidade de um curso a distância é a interatividade entre professores, tutores e alunos. A interação deve ser apoiada em um adequado sistema de tutoria e em um ambiente computacional, especialmente implementados para atendimento às necessidades do aluno.

Nesse sentido, é perceptível que, para alcançar a aprendizagem dos alunos na $\mathrm{EaD}$ com qualidade, mui- tos elementos são fundamentais, como o projeto político pedagógico, a estrutura do curso, a equipe multidisciplinar, o ambiente, seja virtual ou presencial, e os recursos tecnológicos usados na interatividade e interação dos alunos.

Em relação à equipe multidisciplinar, este documento elenca três categorias profissionais essenciais para uma oferta de qualidade: docentes, tutores e pessoal técnico-administrativo. Para os docentes, os referenciais sugerem que o "projeto pedagógico deve especificar claramente em um quadro a qualificação dos docentes responsáveis pela coordenação do curso como um todo, pela coordenação de cada disciplina do curso, pela coordenação do sistema de tutoria e outras atividades concernentes" (BRASIL, 2007) p.20).

Em se tratando dos tutores, o documento explicita:

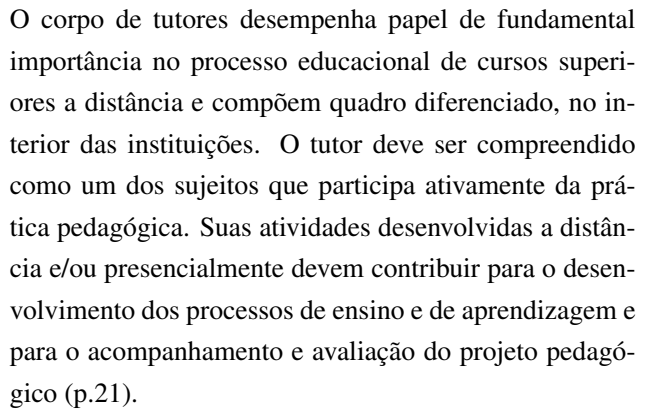

Nesse sentido, é preciso observar atentamente quem está mais diretamente envolvido com o aluno que está vinculado a $\mathrm{EaD}$ : os tutores que atuam nessa modalidade de ensino. O tutor desempenha múltiplas funções, para muitas das quais, geralmente, não foi adequadamente preparado.

Para Marsden (1996, p.223 apud Belloni, 2001, p.79):

\footnotetext{
A definição do papel, das funções e das tarefas docentes em EAD terá de ser necessariamente diferente daquelas do ensino convencional. Naturalmente, a indefinição conceitual e apresentar como se dará a interação entre alunos, tutores, professores ao longo do curso, especificando no projeto pedagógico, em especial, o modelo de tutoria; institucional neste campo reflete-se no papel e nas funções do professor a distância.
}

Assim sendo, as instituições que trabalham com a modalidade de educação a distância precisam capacitar adequadamente e de forma responsável os seus tutores, por meio dos cursos de formação. Nessa formação, deve-se considerar as competências didáticas, pedagógicas e tecnológicas necessárias para se desenvolver o trabalho docente em EAD. 
Nessa perspectiva, a Diretoria de Educação a Distância do Instituto Federal de Educação, Ciência e Tecnologia do Ceará (DEaD-IFCE) capacita seus tutores para atuarem nos cursos de graduação na modalidade semipresencial vinculados à Universidade Aberta do Brasil (UAB) e nos cursos técnicos (e-Tec).

Essa formação tem sido organizada de forma que esses profissionais adquiram competências e habilidades para desempenhar sua função com segurança, responsabilidade e compromisso, partindo do pressuposto que o papel do tutor nessa modalidade de ensino é fundamental como mediador da aprendizagem do aluno.

Apresenta-se neste artigo a formação dos tutores inicial e continuada elaborada pela DEaD-IFCE e implementada no ambiente virtual MOODLE (Modular Object-Oriented Dynamic Learning Environment), onde são mostradas as competências pedagógicas, didáticas e tecnológicas inerentes à formação do tutor,bem como a metodologia usada no curso e os resultados que se tem obtido com as tutorias.

\section{COMPETÊNCIAS PEDAGÓGICA, DIDÁTICA E TECNOLÓGICA}

Demartini e Edelweiss (2001) consideram que para a efetividade do papel do tutor é necessário um conjunto de ações de ensino que assuma diferentes formas, bem como a dependência do contexto em que se insere, dos objetivos que se pretende alcançar, do público alvo que se beneficiará e das condições oferecidas para que se concretize essas ações.

Nesse sentido, para assumir a função de tutor no ensino a distância, é fundamental que seja formado um tutor com perfil multifacetado de competências e habilidades a fim de cumprir as ações que são de sua responsabilidade. De fato, essas ações de ensino devem ser diversificadas no campo pedagógico, didático e tecnológico, uma vez que a sala de aula virtual é heterogênea e assim sendo não se pode conduzir ambientes de aprendizagem como se todos fossem iguais e aprendessem da mesma forma. Essa especificidade também é válida para ambientes de aprendizagem presenciais.

Já para Belloni (2001), o tutor precisa conhecer os processos de aprendizagem, como as metodologias, as teorias que envolvem as relações de aprendizagem, sejam construtivistas ou tradicionais, os processos avaliativos que podem contemplar os ambientes de virtuais de aprendizagem (AVAs), os conhecimentos advindos da psicologia, ciências cognitivas, ciências humanas e ainda desenvolver capacidades relacionadas a pesquisa, a aprendizagem autônoma, a colaboração e a interação.

Fique claro, que os tutores já são profissionais com graduação ou pós-graduação,mas as relações pedagógi- cas para serem usadas em cursos a distância precisam ser redimensionadas, atualizadas e experimentadas pelos tutores em sua própria formação para que venham a desenvolver com seus alunos.

Assim, haverá a necessidade do tutor se adaptar aos modelos educacionais à distância. No ambiente virtual, o professor atua como um dinamizador e facilitador do processo de aprendizagem dos seus alunos, na perspectiva de que esse aluno também assuma o contrato didático para sua aprendizagem.

$\mathrm{Na} \mathrm{EaD} \mathrm{o} \mathrm{aluno} \mathrm{precisa} \mathrm{ter} \mathrm{autonomia} \mathrm{nas} \mathrm{suas}$ ações de aprendizagem, porém não retira a responsabilidade do tutor de ser aquele que media a aprendizagem, tornando o curso para o aluno mais interativo, continuado e envolvente. É importante ressaltar, que o tutor precisa está sempre atento para aqueles alunos que não estão tendo autonomia e capacidade para executar as tarefas exigidas, dando-lhes feedback constante, apoio e incentivo para que retome seu papel dentro do contexto pedagógico em que está inserido.

Ressalta-se também que o tutor deverá conhecer bem as relações das teorias de aprendizagem, como a construtivista, interacionista e instrucionista. É preciso que o tutor perceba a configuração do ambiente virtual utilizado para acompanhar os alunos, se este é voltado para a desvalorização dos conhecimentos prévios, da ausência de reflexão e conduzido por um caminho linear baseado em questões de estímulo-resposta. Se assim for, a tecnologia está apenas fazendo um monitoramento controlado via máquina, em que todos estão sendo conduzidos para a mesma resposta. Portanto, não proporciona situações que levem o aluno a refletir e questionar sobre seus erros e acertos. Essa concepção de ensino baseia-se nas teorias instrucionistas e o tutor deve ter uma percepção crítica e questionadora para ambientes virtuais que assumem essa linha pedagógica.

Por outro lado, se o ambiente virtual de aprendizagem (AVA) do aluno se permeia por propostas pedagógicas, que permitem a interação entre os alunos, a colaboração, a autonomia, a reflexão, a construção do conhecimento e a mediação do tutor, logo está baseado nas teorias construtivista e interacionista. O processo educacional veiculado nesse cenário está centrado na aprendizagem do aluno e assim favorece o tutor para o desenvolvimento da uma tutoria que instiga e questiona seu aluno para que este consiga alcançar uma aprendizagem consolidada na reflexão.

$\mathrm{Na}$ condição de mediador atento, cabe ao tutor perceber que os alunos autônomos serão aqueles que saberão construir sua própria metodologia de estudo diante dos desafios, da solução de problemas individuais e coletivos. Indivíduos autônomos possuem iniciativa, com- 
promisso, disciplina, interagem e encontram os meios para alcançar a melhor forma de aprender.

Para Belloni (2001), em situações de aprendizagem a distância, a interação entre tutor-aluno é fundamental, reforça-se ainda mais quando as técnicas de interação são mediatizadas por emails, listas, fóruns, chats, pois esses recursos facilitam a comunicação e cumpre a função de estabelecer o vinculo entre todos. Esses recursos interativos permitem que os alunos possam colaborar entre si, interagir, discutir e ser mediado pelo tutor. Percebe-se que quando se estabelece a interação efetivamente, os alunos buscarão suprir a ausência de um espaço presencial na medida em que o tutor seja cada vez mais presente no espaço virtual.

Com a interação, o tutor também será capaz de identificar os alunos que melhor organizam seu pensamento, são coerentes em suas ideias, buscam aprender com o outro o que não sabe e dividem também o que sabem. Bem como, reconhecer os alunos mais tímidos e com dificuldades de interagir e poder ajudá-los a superar esses entraves.

Por outro lado, uma das habilidades que o tutor deve ter é saber dosar a sua interação no grupo de alunos, pois as intervenções demasiadas podem bloquear a participação dos alunos e impedir que o aluno alcance sua autonomia. Segundo Palloff (2004) o professor deve aprender a fazer perguntas amplas para atingir o equilíbrio entre interação excessiva e interação insuficiente com o objetivo de transmitir o conteúdo sem sacrificar a interação e a formação da comunidade de aprendizagem.

Em relação às práticas pedagógicas sobre a avaliação na $\mathrm{EaD}$, o tutor terá que avaliar quantitativamente como qualitativamente os alunos. Esta avaliação pode se dar por meios dos ambientes virtuais de aprendizagem, observando interação dos alunos nos fóruns e chats, da postagem das atividades nos portfólios, depuração e reflexão crítica sobre as questões propostas. O tutor, assim, terá como acompanhar, avaliar e mapear o percurso cognitivo de cada sujeito em formação, bem como registrar o processo de desenvolvimento desse aluno, dando-lhe elementos norteadores para que ampliem e retomem a aprendizagem.

Segundo Silva (2006), a avaliação de aprendizagem na sala de aula online deve se basear na autonomia do aprendiz, no diálogo professor e alunos, na participação de cada um e na construção da comunicação e do conhecimento. Para o autor é preciso se preparar para a aprendizagem e para as avaliações interativas nessas salas de aula, disponibilizando-se de informações, propostas de trabalho, links, imagens, músicas, filmes, além do planejamento do curso, especificando os objetivos e con- teúdos programáticos, e assim situar para o aluno o processo de avaliação.

Observando o contexto didático, percebe-se que é necessário que o tutor tenha a formação especifica na área em que irá atuar na tutoria dos alunos e saber relacionar as habilidades e competências inerentes a sua disciplina com as competências tecnológicas e pedagógicas. Na perspectiva globalizada, a formação dos professores é buscar a compreensão dos conceitos teóricos para que possam ser redimensionados em desenvolvimento cientifico e tecnológico.

Segundo Martins (1989), didática é:

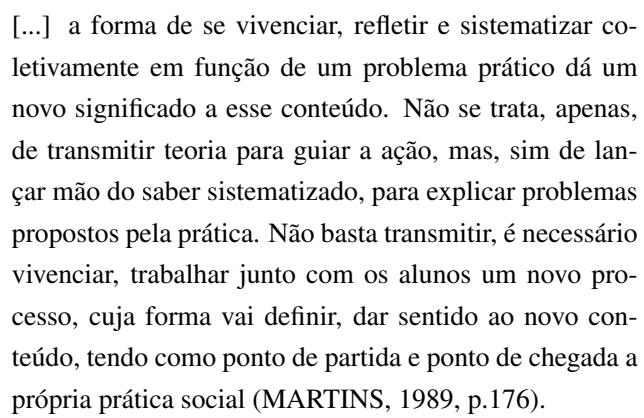

O tutor precisa constantemente atualizar-se e exercer papel de orientador, facilitador e incentivador da sua disciplina, ficando atento também não apenas no que deve ensinar aos seus alunos, mas no que eles precisam aprender para tornarem-se profissionais competentes diante da sociedade globalizada e tecnológica.

No âmbito da competência tecnológica é fundamental que o tutor tenha habilidade com os recursos tecnológicos no qual irá manusear e estar ciente das influências metodológicas que a utilização desses recursos implica na aprendizagem dos alunos na modalidade da educação distância. É importante observar que os ambientes informatizados, não são capazes de promover mudanças nos processos de ensino ou implantar processos mais modernos à educação. É necessário que haja integração e mediação adequadas entre as ferramentas tecnológicas e os projetos pedagógicos propostos para a EaD de modo que se criem novas possibilidades para o aprendente.

Vale ressaltar que a relação do tutor-aluno por meio do ambiente virtual através das ferramentas assíncronas (fóruns, portfólios, emails) e ferramentas síncronas (chats, videoconferências) são suportes técnicos que mediatizam a interação e facilitam a comunicação. Entretanto, na concepção de Belloni (2001) a educação não é apenas um sistema de máquinas que visam à informação ou simplesmente uma mera transmissão de informações. A educação deve ir muito além, ou seja, deve problematizar o saber, contextualizar os conheci- 
mentos, colocá-los em perspectiva, para que os aprendentes possam apropriar-se deles e utilizá-los em outras situações.

Dessa forma, se os tutores forem formados fazendo uso das tecnologias disponíveis e tiverem conhecimentos das propostas pedagógicas e didáticas estas ações poderão facilitar a sua atuação no ambiente virtual, e se perceberem, que a prioridade é formar um ambiente colaborativo com seus alunos, o resultado poderá vir a ser cursos que os alunos atinjam seus objetivos e alcancem a aprendizagem. Segundo Pratt (2004), quando os cursos são planejados e desenvolvidos com a interatividade em mente, uma mudança ocorre, com os alunos tornando-se mais autônomos e descobrem que a aprendizagem também pode vir da interação com os colegas.

Aliada as competências pedagógica, didática e tecnológica na seção seguinte, apresenta-se a metodologia aplicada na formação dos tutores do DEaD-IFCE, cujo ambiente virtual de aprendizagem utilizado para interação foi o MOODLE.

\section{METODOLOGIA}

A proposta para o curso formação de tutores é baseada na modalidade semipresencial, em que há encontros presenciais e a interação acontece pelo ambiente virtual MOODLE.

O MOODLE é um software de licença livre e gratuito de apoio à aprendizagem. Constitui-se em um dos ambientes de aprendizagem mais usados hoje em dia por se tratar de um sistema aberto. É desenvolvido colaborativamente por uma comunidade virtual, que reúne programadores e desenvolvedores de software livre, administradores de sistemas, professores, designers e usuários de todo o mundo. Encontra-se disponível em diversos idiomas, inclusive em português.

Para participar do curso de formação é aberto um edital de seleção onde se determina quais as áreas de atuação que os tutores selecionados atenderão, conforme as demandas solicitadas.

Após serem selecionados pelo edital, de acordo com os requisitos estabelecidos, o tutor passa primeiro pelo curso de formação aonde irá se capacitar para as habilidades e competências inerentes as funções de tutoria.

No edital são especificadas algumas das funções as quais os futuros tutores deverão ter, como: conhecer os materiais didáticos da disciplina, procedimentos e recursos tecnológicos de apoio às atividades; acompanhar a frequência dos alunos, as atividades virtuais e presenciais; identificar alunos com dificuldade de acesso ou com baixo índice de participação na disciplina e tomar as devidas providências para o seu retorno ao curso e outras.
No processo de formação os tutores passam a posição de alunos/cursistas e vivenciam através da própria experiência o papel de aluno. Assim sendo, vivenciam esse processo como alunos/cursistas para posteriormente assumirem o papel de tutor.

O público-alvo do curso é constituído por profissionais que possuem graduação com experiência no magistério ou pós-graduação na área de matemática e/ou turismo ou áreas afins, uma vez que a DEaD- IFCE atende a demanda desses cursos.

A primeira etapa do curso é o encontro presencial, onde todos os alunos selecionados recebem as explicações referentes ao curso por um professor/tutor responsável pela formação do grupo. É importante ressaltar que esse encontro é de fundamental importância para que os alunos/cursistas saibam a metodologia do curso, bem como irão desenvolver suas atividades no AVA MOODLE.

No encontro presencial, apresenta-se a estrutura da Diretoria de Educação a Distância do IFCE (Figura1), assim como os papéis que cada um possui, seja no âmbito da gestão, da divisão de apoio administrativa e acadêmica, na divisão pedagógica e na divisão técnica.

A segunda etapa do curso será a distância, que por sua vez, tem como finalidade propiciar o encontro virtual entre os participantes do curso: alunos/cursistas e professor-tutor.

Por meio do ambiente virtual MOODLE os alunos fazem a interação com os colegas, produzem as atividades individuais, disponibilizam as tarefas nos fóruns e tarefas e participam dos Chats, previamente agendado pelo seu tutor (Figura2).

Para promover a discussão sobre os assuntos dos módulos são abertos fóruns onde os alunos precisam interagir, postando mensagens sobre a compreensão que tiveram sobre os conteúdos propostos, bem como refletir criticamente sobre as mensagens dos demais colegas. Além dos fóruns, os alunos também possuem outras atividades no AVA, como: chats (bate-papos online), portfólios, quizes (questionários) e a função de saber elaborar uma aula ou curso no ambiente MOODLE.

As atividades propostas para elaboração de uma aula no AVA fará com que o aluno/cursista aprenda a configurar o ambiente MOODLE, ou seja, saiba postar aulas, abrir ou fechar os fóruns, avaliar o aluno, alterar a agenda, enviar mensagens, promover um chat entre outras ações pertinentes ao AVA.

O curso virtual no ambiente MOODLE possui cinco aulas que discorre sobre apresentação de cada aluno e as suas expectativas em relação ao curso; a evolução da educação a distância e os seus referenciais de qualidade; a autonomia; as ferramentas síncronas e assíncro- 


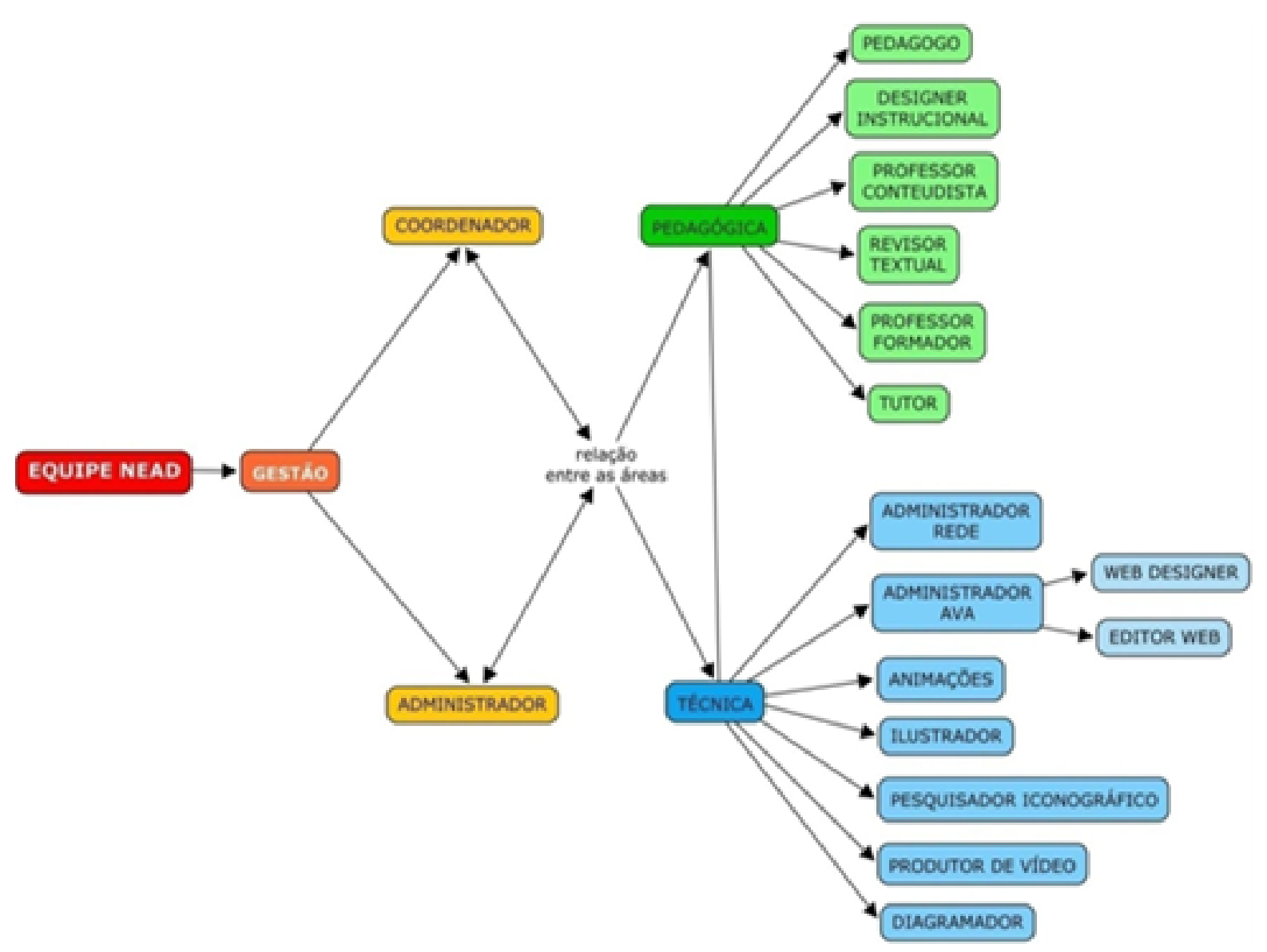

Figura 1: Estrutura da Diretoria de Educação a Distância (DEaD/IFCE). 
FORMAÇÃO DE TUTORES NA DEAD/IFCE: COMPETÊNCIAS E HABILIDADES NECESSÁRIAS

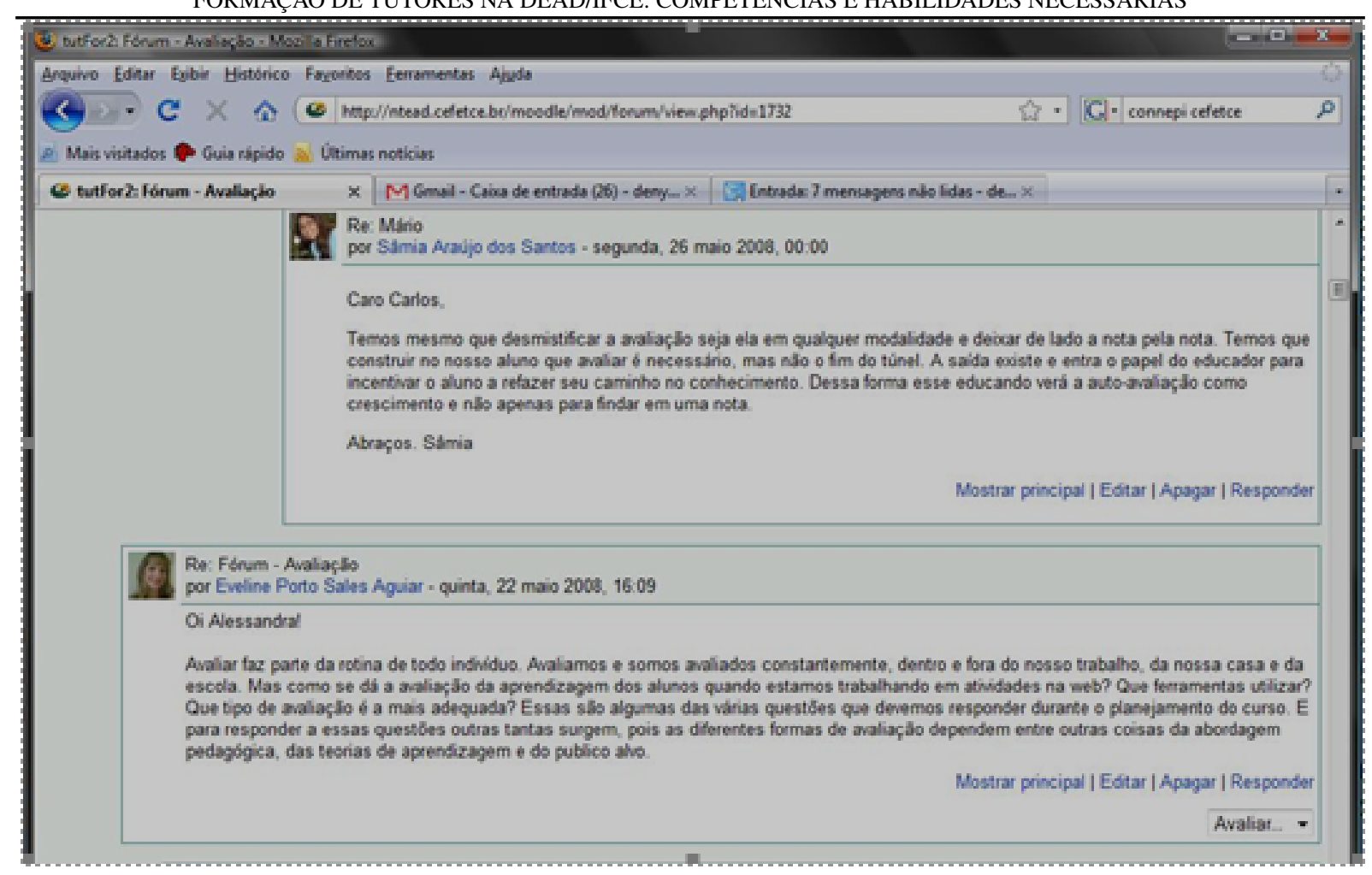

Figura 2: Fórum de discussão no MOODLE.

nas do MOODLE e os processos avaliativos aplicados em AVAs.

Durante o curso de formação os alunos/cursistas são avaliados por um sistema e modelo de avaliação denominado Learning Vectors (Vetores-Aprendizagem) (SALES, 2010, SALES; BARROSO; SOARES, 2012). Esse mesmo modelo é usado para avaliação dos alunos que fazem os cursos de graduação, técnicos e de aperfeiçoamento oferecidos pela Diretoria de educação a Distancia/IFCE (Figura3).

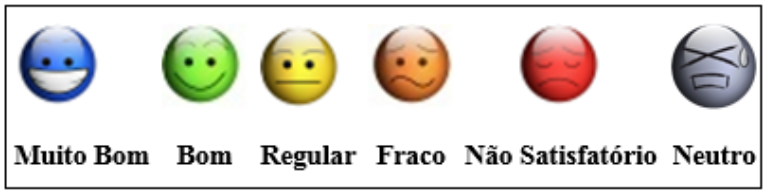

Figura 3: Learning Vectors - Escala de Menções Qualitativas.

A avaliação dos alunos no curso de formação é continuada e progressiva. O aluno é avaliado quantitativamente como qualitativamente, ou seja, todas as participações nas atividades propostas no ambiente virtual são acompanhadas através desse instrumento de avaliação, em que se observa a interação, colaboração, a autono- mia e a contribuição pertinente ao tema abordado que possibilita a melhoria no ensino e na aprendizagem.

A terceira e última etapa do curso trata-se do segundo encontro presencial com os alunos/cursistas e seu professor-tutor. Neste momento reforça-se a responsabilidade e compromisso que os cursistas irão assumir quando atuarem como tutores.

Os alunos/cursistas para exercerem a função de tutores no IFCE devem ser aprovados no curso de formação de tutores a distância, com média mínima de 7,0 e frequência de $75 \%$.

Ressalta-se ainda que o tutor passa por essa formação inicial, mas durante seu percurso na DEaD ele permanece em contínua formação,uma vez que esta não pode ser estanque,mas precisa ser redimensionada constantemente.

Essa sistematização metodológica para o Curso de Formação de Tutores pretende auxiliar na atuação desses profissionais referenciando o compromisso diante das tutorias que serão de sua responsabilidade.

\section{CONSIDERAÇÕES FINAIS}

Este artigo tratou da formação de tutores, reportandose as relações interpessoais e humanísticas inerentes ao 
educador que se deseja formar, uma vez que vínculos devem ser estabelecidos entre professor-tutor e seus discentes para que se forme uma relação de confiança. Isto poderá contribuir para minimizar a ausência física, proporcionado pelo ensino a distância.

Os resultados alcançados no curso de formação de tutores do IFCE tem sido satisfatório, uma vez que a maioria dos participantes conclui o curso e também são aprovados obtendo um bom desempenho.

O trabalho de tutoria bem planejado, em que não faltam feedbacks constantes, pode garantir uma evasão menor.

$\mathrm{Na}$ metodologia apresentada neste artigo incita-se a interação e a colaboração entre os pares como medida que ajuda a desenvolver a autonomia para a construção do saber coletivo.

Espera-se que metodologias veiculadas em EaD estejam à frente de toda e qualquer escola progressista que acredita no poder que a tecnologia dispõe.

É importante ressaltar que os programas de capacitação estão em constante atualização, visto que, a dinâmica dos cursos, as relações com os estudantes nos polos, as avaliações, irão alimentar novos aspectos a serem trabalhados.

Acredita-se que as distâncias podem ser superadas quando se tem um professor-tutor que faz um acompanhamento constante, oferece feedbacks diários aos discentes, bem como atua como um profissional sério e comprometido com a construção do conhecimento (BRASIL, 2004)

\section{REFERÊNCIAS}

BELLONI, M. L. Educação a distância (coleção educação contemporânea).2.ed.Campinas, SP: Autores Associados. 2001. 115 p.

BRASIL. Portaria $N^{\circ} 4.059$, de 10 de dezembro de 2004. 2004. Disponível em: <http://meclegis.mec.gov. br/documento/view/id/89>

Referenciais de qualidade para educação superior a distância. MEC-Ministério da Educação, Secretaria de Educação a Distância(SEED), 2007. Disponível em: <http://portal.mec.gov.br/seed/arquivos/pdf/ legislacao/refead1.pdf> Acesso em: 22 abr. 2014.

DEMARTINI, G.; EDELWEISS, N. Autenticação de alunos e geração e análise de log de acessos em cursos de ensino a distância. cadernos de informática -vol.I. Porto Alegre, Instituto de Informática, UFRGS, 2001.
\& desafio: uma perspectiva construtivista. [S.1.]: Educaçäo \& Realidade, 1992.

MARTINS, P. L. O. Didática teórica/Didática prática:para além do confronto. São Paulo: Loyola, 1989.

PALLOFF, R. M. O aluno virtual:um guia para trabalhar com estudantes on-line/ Rena M. Palloff e Keith Pratt; trad. Vinícius Figueira. Porto Alegre: Artmed, 2004. 216 p.

SALES, G. L. Learning Vectors (LV): um modelo de avaliação da aprendizagem em EaD online aplicando métricas não-lineares. Tese (doutorado em Engenharia de Teleinformática) — Departamento de Engenharia de Teleinformática, Universidade Federal do Ceará, Fortaleza, 2010. $239 \mathrm{f}$.

SALES, G. L.; BARROSO, G. C.; SOARES, J. M. Learning vectors (LV): Um modelo de avaliação processual com mensuração não-linear da aprendizagem em ead online.In. Revista Brasileira de Informática na Educação, v. 20, n. 1, 2012.

SILVA, M. O fundamento comunicacional da avaliação da aprendizagem na sala de aula online.In: SILVA, marco e SANTOS, edméa (orgs). avaliação da aprendizagem em educação Online. Loyola, São Paulo, 2006.

HOFFMANN, J. Avaliaçäo: mito \& desafio: uma perspectiva construtivista. In: Avaliaçäo: mito 